\title{
CHRONIC GRANULOMA OF THE ORBIT CAUSED BY GREASE-GUN INJURY*
}

\author{
BY \\ N. L. DALLAS \\ St. Thomas's Hospital, London
}

\section{Case Report}

A motor cycle mechanic aged 39 years sustained an injury to the inner corner of the left eye with a jet of oil from a grease-gun. In spite of considerable bruising of the lids and conjunctiva, discomfort in the eye was minimal, so he was not referred to Moorfields until 4 days after the accident.

Examination.-The right eye was found to be normal and the visual acuity $6 / 6$ unaided. In the left eye the visual acuity was 6/12 unaided. There was gross bruising and swelling of the lids and conjunctiva and slight ptosis (Figs 1-3). The eye was proptosed approximately $10 \mathrm{~mm}$.

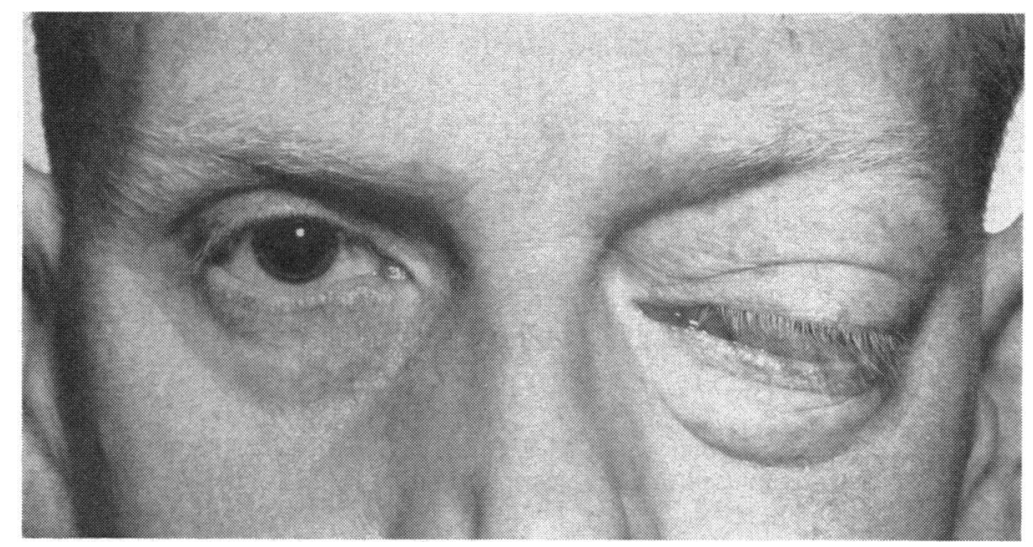

Fig. 1.-Appearance of left orbit on February 6, 1963, one week before operation.

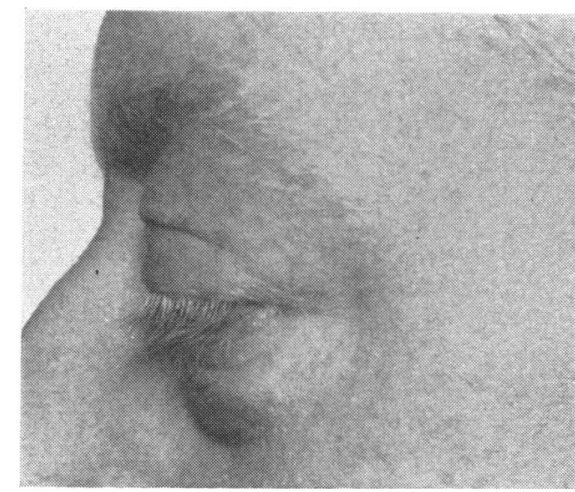

FIG. 2.-Lateral view of left orbit.

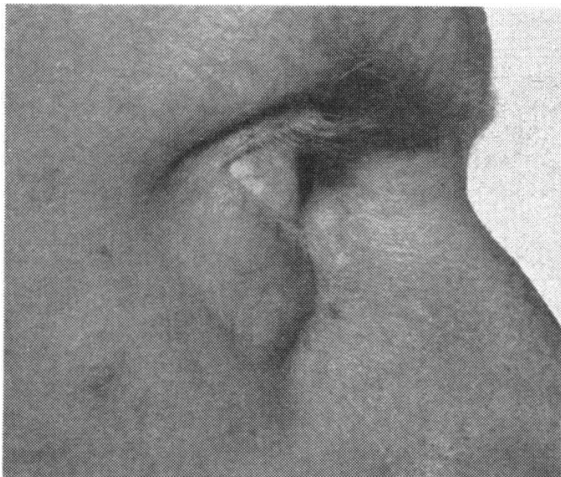

Fig. 3.-Lateral view of right orbit, for comparison.

* Received for publication May 16, 1963. 
and displaced downwards and outwards with limitation of ocular movements, especially elevation and adduction. The media were clear, but there was congestion of the retinal veins and swelling of the optic disc. Irregular field loss, mainly in the upper half of vision, was found. No bony injury was seen on $x$-ray examination.

Treatment.-The bruising quickly settled after admission to hospital, whilst the other signs remained unchanged. It was thought that a course of systemic steroids might reduce the inflammatory manifestations, and $15 \mathrm{mg}$. Prednisolone was given daily for 6 weeks, and reduced to $5 \mathrm{mg}$. daily for a further 4 weeks.

Progress.-There was little change in the physical signs during the next 3 months. The scotomata varied somewhat. There was enlargement of the blind spot, a small absolute scotoma in the upper nasal quadrant, and a large relative scotoma to a $2 \mathrm{~mm}$. white target in the upper temporal quadrant, breaking through to the periphery. The visual acuity remained at 6/12.

The possibility that the history was misleading and that another orbital lesion existed had to be considered, and the patient was admitted to St. Thomas's Hospital. Further $x$ rays of the orbit were normal. There was no evidence of mucocele or infection around the orbit. The finding of an enlarged pituitary fossa without erosion was thought by a neurologist to be familial even though a latent eosinophilic tumour was possible on the grounds that the patient had attained a height of $6^{\prime} 3^{\prime \prime}$ by the age of 12 . There was, however, no clinical evidence of pituitary dysfunction.

Operation.-The left orbit was explored via an antero-temporal approach by Mr. Harvey Jackson. An encapsulated oval-shaped swelling 3-4 cm. long was found lying in the muscle cone between the superior rectus and the optic nerve. As the upper and outer walls of granuloma were dissected away, a globule of grease was found, and this was subsequently removed leaving behind the floor and inner wall of the granuloma. A laboratory report confirmed the nature of the released fluid.

Result. -2 months later there was still no significant change in the physical signs, though there had been a transient, complete ptosis in the post-operative period.

\section{Comment}

Grease-gun injuries to the hand have been well described. They are characterized by pain and relatively few external signs. Later there occurs a crippling fibrosis, a chronic discharging sinus, and necrosis. In contrast, the symptoms of the case described here were few but the signs were marked and persistent.

I wish to express my thanks to Mr. Harold Ridley for permission to publish this case. 